\title{
Repensar la economía y la sociedad postpandemia: Superar la desigualdad
}

\section{Rethinking the post-pandemic economy and society: Overcome inequality}

\author{
María Dolores Lorenzo* \\ UNIVERSIDAD NACIONAL AUTÓNOMA DE MÉXICO \\ ASOCIACIÓN LATINOAMERICANA E IBÉRICA DE HISTORIA SOCIAL
}

\section{RESUMEN}

En América Latina, aliviaremos los efectos de la emergencia sanitaria con los recursos de las economías locales y las condiciones materiales y sociales con las que cuentan las sociedades. $\mathrm{Si}$ bien veremos escenarios de recuperación excepcionales, las carencias y las condiciones desiguales que predominan en la región se acentuarán. Sabemos que las catástrofes no crean las desigualdades sociales, pero sí las agravan y las muestran con toda su crudeza.

Palabras clave: Desigualdad, pobreza, catástrofe, salud

\begin{abstract}
In Latin America, we will alleviate the effects of the health emergency with the resources of local economies and the material and social conditions available to societies. While we will see exceptional recovery scenarios, the gaps and uneven conditions prevailing in the region will be accentuated. We know that disasters do not create social inequalities, but they do aggravate them and show them with all their rawness.
\end{abstract}

Keywords: Inequality, poverty, catastrophe, health

*madolores@gmail.com 


\section{DESIGUALDAD ESTRUCTURAL}

nfrentamos los desastres a partir de nuestra visión del mundo y según los usos y costumbres que cada sociedad construye para protegerse. La recuperación después de una emergencia desastrosa involucra decisiones individuales y colectivas las cuales son parte de un proceso histórico que nos remite a un pasado inmerso en contextos comunes. En este sentido, en América Latina, aliviaremos los efectos de la emergencia con los recursos de las economías locales y las condiciones materiales y sociales con las que cuentan las sociedades. De tal manera, si bien veremos escenarios de recuperación excepcionales, de manera generalizada, las carencias y las condiciones desiguales que predominan en Latinoamérica se acentuarán. Sabemos que las catástrofes no crean las desigualdades sociales, pero sí las agravan y las muestran con toda su crudeza.

En estos meses de pandemia, podríamos enlistar diversos ejemplos de las experiencias calamitosas vividas por los hombres y las mujeres, por los indigentes y las diferencias con quienes han tenido los recursos para sortear la pandemia. En las redes sociales y en los periódicos han circulado noticias que redundan en las múltiples formas de exclusión por género, por etnicidad y según la clase social a la que pertenecen personas y comunidades vulnerables. Los medios de difusión han sido enfáticos en mostrar los rostros de los grupos mermados por sus posibilidades de sobrevivir, cuya situación da cuenta de las serias dificultades de la recuperación, por ejemplo, de las mujeres violentadas, los huérfanos, los ancianos sin ayuda, los desempleados, los enfermos y los discapacitados.

Es posible que la ruta de las políticas públicas postpandemia puedan atenuar algunos mecanismos que reproducen la desigualdad y los procesos de exclusión social a través de subsidios y de la universalización de algunos servicios destinados a solventar carencias individuales. Ante la actual pandemia se han desarrollado muy distintos modelos para mejorar los daños y precisar la dirección e intensidad de la reconstrucción focalizada en áreas y en grupos muy específicos, grupos y áreas vulnerables en nuestros territorios. Por eso, en esta platica quiero señalar algunos aspectos que las políticas 
públicas postpandemia tendrán, en mi opinión, que retomar para reconstruir nuevos escenarios después de la devastación de la pandemia.

\section{Carencias que SE MUltiplican}

En el caso de México casi un $60 \%$ de la población ocupada se ubica en el sector informal. Un gran número de personas viven de su ingreso diario y pese a los riesgos del contagio salieron a la calle a buscar un medio de subsistencia. Estas son personas que forman parte de los pobres y de los vulnerables por carencias sociales y pobreza por ingresos. Estos son parte de los 61 millones de mexicanos considerados pobres y vulnerables. Son quienes carecen de asistencia social de servicios de salud y que, ante los despidos de esta pandemia, viven en un mundo que carecen de seguros de desempleo.

El trabajo informal y la precarización del salario son cuestiones centrales para repensar las políticas postpandemia. Los datos del CONEVAL (Consejo Nacional de Evaluación de la Política de Desarrollo Social) respecto de la pobreza nos brinda la posibilidad de comparar los años del 2008 al 2018, el resultado muestra que la gran mayoría de quienes han sido despedidos viven en un mundo que carecen de seguros de desempleo. En cuanto a los desempleados, el problema que deja esta catástrofe no es solamente la falta de ingresos que va a suscitar vivir sin salario, sino también que éstos tardarán mucho tiempo en encontrar un nuevo trabajo. Para estos grupos, quizás, la solución sería contener la caída del ingreso y crear empleos, pero existe el riesgo de un traspaso del empleo formal al empleo informal, con lo cual también tendríamos que proteger este tipo de trabajador para que cuente con acceso a la provisión de ingresos, al bienestar y a los servicios públicos.

Siguiendo la acumulación de carencias de este $60 \%$ de la población que trabaja en el sector informal, cabe señalar que en este grupo de la población predomina la obesidad por carencias nutricionales. Así también, en este porcentaje de la población, se concentran los diabéticos, los que padecen enfermedades renales 
y los que presentan hipertensión. Cabe reiterar una vez más que la mayoría carece del tratamiento médico adecuado, porque no tienen acceso a los sistemas de salud especializados ni tampoco a la seguridad social. Así, para paliar la ausencia de estos servicios, los hogares destinan más o menos el $41 \%$ de sus gastos en salud incluyendo medicamentos, gastos catastróficos y de emergencia.

La carencia de este grupo de la población que representa a este $60 \%$ de mexicanos se vincula a la calidad de la vivienda: no habitan en una vivienda digna, para la construcción de estas casas se emplearon materiales ligeros, duermen más o menos tres personas por habitación y casi la mitad de estas habitaciones carece de acceso a los servicios básicos, entre ellos el agua, por lo cual además de tener límites para llevara cierto distanciamiento, en muchos casos, lavarse las manos con la frecuencia, según recomendaban los epidemiólogos, no es una acción que pueda hacerse con regularidad. Dadas estas condiciones es raro que el número de contagios en México no supere significativamente el porcentaje de contagiados en países que no tienen estas carencias. Seguramente, para acercarnos a una versión realista, habrá que considerar el subregistro y las pocas pruebas que se han hecho en México para registrar los contagios.

Otro aspecto para reflexionar en un mundo postpandemia es el tipo de violencia que se intensificó durante el confinamiento. Entre febrero y marzo de 2020, los delitos asociados a la violencia de género aumentaron casi un $13 \%$. Además, cabe recordar que México ya tenía uno de los índices más altos de feminicidios, con más de 800 casos reportados por año. Antes de la emergencia epidemiológica, en México, se reportaban altos niveles de violencia familiar, pero según datos de las organizaciones de la sociedad civil sabemos que la presión económica y el confinamiento, además de las condiciones precarias de las familias, suscitaron un incremento significativo de llamadas de auxilio y orientación para contener violencia en los hogares. Asimismo, en un análisis de los datos de los Refugios Nacionales se encontró que las posibilidades de emprender una vida independiente fuera de los refugios y fuera de los espacios de los hogares donde hay violencia intrafamiliar se dificultaron ampliamente, por la escasez 
de opciones laborales y también las posibilidades de autonomía de están limitadas porque las escuelas han permanecido cerradas y los hijos deben permanecer con las madres.

Podemos adelantar que la presión por la falta de ingreso aunado a la tensión que genera el hacinamiento en espacios de convivencia violenta, la carencia de servicios básicos y la incertidumbre ante el contagio sin expectativas de recibir atención, incidirán en una manera distinta de percibir los medios de subsistencia y la percepción de bienestar, no solo por la enfermedad y la muerte que alteró de manera fehaciente a las familias, sino por otros daños sobre los grupos vulnerables de la población.

Sabemos que para cubrir la necesidades básicas los grupos de la población ubicados en la base de la pirámide social salió a la calle en busca de sustento diario, enfrentó al virus y se expuso a la muerte debido a la acumulación de carencias. Este grupo de la población no tuvo acceso a la seguridad social.

Entre las medidas de emergencia tomadas por el gobierno para paliar los efectos de la pandemia, el Instituto Mexicano del Seguro Social (IMSS), donde están afiliados el grueso de los trabajadores, abrió sus puertas para los no afiliados en estos últimos meses cuando presentaban casos de COVID. El regreso a la normalización ¿desplazará a los no afiliados del acceso a los servicios públicos? Me parece que la apertura del IMSS pudo contener en la fase de pandemia la letalidad en los estratos sociales más bajos; sin embargo, habrá que esperar a que pase la emergencia para sopesar sus efectos, pues es probable que las repercusiones afecten de manera muy directa a la subsistencia de la población que era ya de por sí vulnerable.

También tenemos que considerar en el recuento de daños la territorialización de los efectos de la pandemia, porque lo que comenzó en México como una epidemia concentrada en las áreas urbanas ha ido alcanzando poco a poco los lugares más alejados y menos urbanizadas, mientras el número de contagios crece, los nuevos lugares que el COVID alcanza son los de mayor vulnerabilidad, tanto en términos demográficos, socioeconómicos, como de accesibilidad a los servicios de salud. Dadas las desigualdades 
de acceso a los servicios en el ámbito urbano y en el rural no fue lo mismo enfermarse en Ciudad de México que en una comunidad otomí de la Sierra Madre Occidental. La distribución territorial diferenciada reflejará, sin duda, las zonas de mayor vulnerabilidad ante la epidemia y las difíciles implicaciones que va a tener para reconstruirse cada región, cada área y cada localidad, considerando por ejemplo, el rezago de servicios hospitalarios en las zonas rurales.

\section{Protección SOCIAL Y LA HAZAÑa FISCAL}

Considerando la capacidad de resiliencia de las sociedades ante el desastre, me parece que habría que insistir en dos puntos: el primero tiene que ver con pobreza, avanzar hacia la institucionalización de un sistema de protección social y de salud de cobertura universal con una oferta integral de prestaciones y con calidad en los servicios. En México, el sistema de asistencia y salud muestra que, si bien se ha perseguido sobre todo los últimos 10 años la universalidad, estos han sido sistemas muy frágiles, precarios, heterogéneos y con bajos estándares de provisión a las poblaciones en situación de pobreza y excluidas. Además, en México, cumplimos cabalmente con la ley del cuidado inverso, que establece que los peores estándares de provisión de salud están disponibles para la atención de la población con mayores necesidades. Por otro lado, valga decir que están concentrados en la Ciudad de México y que esta es otra manifestación del acceso desigual que históricamente ha operado en nuestro país. Ahora bien, si queremos avanzar hacia un nuevo sistema de cobertura universalista, el segundo aspecto sobre el cual hay que insistir es en una reforma fiscal porque se requiere realmente un financiamiento con un cargo a impuestos generales que solamente será sostenible a largo plazo con una profunda transformación del régimen que busque la redistribución justa del ingreso con tasación progresiva en la que podamos revisar, por ejemplo, las exenciones de impuestos a las grandes empresas y a los regímenes especiales de los empresarios pequeños y medianos que tienen condiciones usualmente de excepción. 
Quizás valdría también en esta revisión fiscal, aunque no sea un tema prioritario, pensar en las formas de relación que tendrá el Estado con las organizaciones de la sociedad civil y aquellos sectores que en México están muy por detrás de América Latina que es el sector de la filantropía. Esta reforma fiscal ha sido una tarea que ha ido quedando pendiente desde hace varios sexenios y también, aunque nos parezca raro este gobierno que apuntaba hacia un proyecto más de izquierda, tampoco se ha proyectado una reforma fiscal de esta dimensión. Bajo el argumento de fomentar la inversión de las grandes empresas o debido a la imputación de corrupción de las autoridades, lo cierto es que cobrar impuestos nunca ha sido fácil. Para el caso de México, me parece que hoy la reforma fiscal encontraría un argumento coyuntural: recaudar más dinero de la mano de una reforma social que garantizará un sistema de protección como el que señalábamos, universal y sostenible con un seguro de salud o un seguro de vida y una pensión mínima para todos los mexicanos. Esta sí que sería una innovación que contribuiría de alguna manera a no seguir pagando los costos de las inequidades sociales que en nuestros países donde la desigualdad se manifiesta en forma de inseguridad, violencia y humillación.

\section{CONClusión, UnA MIRAdA DESDE LA HISTORIA}

Con una reflexión desde la historia me parece que podemos buscar en las epidemias del pasado todo aquello que se pueda aprender. Quizás con la convicción de que la historia es maestra de la vida, puede ser útil volver a revisar la historia siempre y cuando sepamos combinar, en la toma de decisiones, el sentido del rumbo de los casos análogos que hay en el pasado con la sensibilidad de saber adaptarlos al tiempo vital.

A los historiadores nos toca reconocer los diferentes contextos en escenarios de pandemias pretéritas y destacar las continuidades como los cierres de fronteras, las cuarentenas y los toques de queda que son prácticas que limitan los riesgos del contagio y muerte, pero siempre imponen costos económicos. La historia ha mostrado que estas medidas impactan de manera directa en las formas de subsistencia 
de las personas y por eso, desde la destrucción masiva de la peste en 1348, todos los reinos y ciudades europeas en la postpandemia dictaron leyes sobre trabajo y normas que controlaban los precios de alimentos y los costos de la vida. Quizá garantizar las formas de subsistencia debía ser la primera lección que deberíamos aprender de la historia y las formas de reconstrucción. También es sabido que, después de una pandemia, para contener los riesgos de la recurrencia de una catástrofe suele fomentarse la inversión en aquello que produce bienestar, sobre todo en infraestructuras de asistencia y salud, pero también en investigación científica. Así, en los periodos postpandemia, se han construido grandes catedrales, hospitales, hospicios y se han modificaron los protocolos de investigación, pues se conoce que esta es una manera de fortalecer a una sociedad ante las recurrencias catastróficas por epidemia. No hay una respuesta certera para la reconstrucción del mundo después de la pandemia, pero sí podemos apuntar algunos los criterios para pensar y revisar la vida en sociedades que buscan las mejores prácticas para superar el desastre.

Fecha recepción: 2 de julio de 2020

Fecha aceptación: 20 de julio de 2020

Versión final: 3 de octubre de 2020 